\title{
Collisional Activation of a Series of Homoconjugated Octadecadienoic Acids with Fast Atom Bombardment and Tandem Mass Spectrometry
}

\author{
Janeen S. Crockett and Michael L. Gross \\ Midwest Center for Mass Spectrometry, Department of Chemistry, University of Nebraska-Lincoln, \\ Lincoln, Nebraska, USA
}

William W. Christie

Hannah Research Institute, University of Glasgow, Ayr, Scotland

\author{
Ralph T. Holman
}

The Hormel Institute, University of Minnesota, Austin, Minnesota, USA

High-energy collisional activation (CA) of long-chain fatty acid ions induces decompositions that occur remote from the charge site. These charge-remote fragmentations (CRFs) have been shown to provide much structural information. In this report, the CRF of a continuous series of 12 homoconjugated octadecadienoic acids was studied with fast atom bombardment and tandem mass spectrometry. Each fatty acid was desorbed as the carboxylate anion, $[\mathrm{M}-\mathrm{H}]^{-}$, the dilithiated species, $[\mathrm{M}-\mathrm{H}+2 \mathrm{Li}]^{+}$, or the bariated species, $[\mathrm{M}-\mathrm{H}+\mathrm{Ba}]^{+}$, giving three ways of localizing the charge. A characteristic pattern is generated for CRF of the 1,4-diene functional group, and this allows for the rapid identification of the functional group and its location on the chain. Minor variations of this pattern are observed for the different ionic precursors and for different locations of the double bonds. Furthermore, there are a few complications from different types of charge-proximate reactions, especially of the fatty acid carboxylates. (J Am Soc Mass Spectrom 1990, 1, 183-191)

$\mathrm{F}$ ast atom bombardment (FAB) and tandem mass spectrometry (MS/MS) have been shown to be useful for the characterization of functional groups on long-chain fatty acids [1,2]. Decompositions occurring remote from the charge site can be induced by high-energy collisional activation (CA). For example, when a saturated fatty acid undergoes collisionactivated decomposition (CAD), cleavages occur at all of the $\mathrm{C}-\mathrm{C}$ single bond locations. This involves a hydrogen rearrangement and the elimination of $\mathrm{H}_{2}$ and a neutral alkene (Scheme I). The mechanism by Jensen et al. [3] involves a six-membered transition state, and

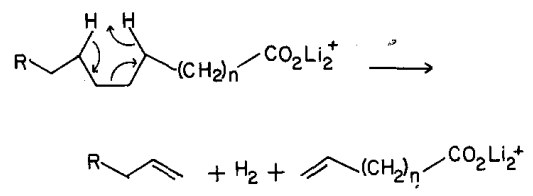

Scheme I

Address reprint requests to Michael L. Gross, Department of Chemistry, University of Nebraska, Lincoln, NE 68588-0304. there is evidence that the fragment is a terminally unsaturated acid [4]. Recent review articles on this subject are available to the interested reader [5-8].

Functional groups along the acid chain interrupt the charge-remote fragmentation (CRF) pattern for an nalkyl group. It is this interruption that permits identification of the functionality and determination of its location. Functional groups on fatty acids that have been easily identified include both single and multiple double bonds [9-11] and branch points [12], as well as epoxides, cyclopropane rings, cyclopropene rings, and hydroxyl groups [1,2]. Previous research was done by examining the consequences of varying the chain length and the location of the group on the chain. Charge has been successfully localized as a carboxylate anion [9] and as a dilithiated carboxylate cation [11]. Sufficient data exist that some comparisons can be made about activating carboxylate versus dilithiated species. The two charged species offer equivalent information in most cases, although the lithiated species can be activated more effectively for polyunsaturated and shorter chain fatty acids $[2,10,11]$. Nevertheless, no extensive series of fatty acids has been studied nor 
has a systematic comparison of charge-localizing methods been made.

This is a report of CRF in which an extensive series of isomeric fatty acids has been utilized. The series affords the opportunity to look at the effects of double bond location on decomposition. Although previous work was done with a wide variety of compounds, chain lengths, and functional groups, there has not been an opportunity to examine CAD systematically as a function of moving the functional group one carbon at a time away from the charge site. Specifically, a series of homoconjugated octadecadienoic acids were investigated by using FAB combined with collisional activation tandem mass spectrometry (MS/CA/MS). The series studied includes all straight-chain methyleneseparated diene isomers from the 3,6 to the 13,16 positions. Of the work reported here, particular emphasis is placed on the actual decomposition and structural applications. Mechanistic possibilities are discussed, but details are reserved for future investigation.

Homoconjugated fatty acids have been of interest for quite some time. cis,cis-9,12-Octadecadienoic acid (linoleic acid) was shown, in 1929, to be essential to animal nutrition [13] and is found in all normal animal tissues. The 5,8,6,9,7,10, and 8,11 isomers are also found in nature [14-17]. This series of methyleneseparated cis,cis-octadecadienoic acids was synthesized for metabolic studies to elucidate the structure essential for biological activity of linoleic acid. Their physical and spectroscopic properties were reported previously [18]. We are now continuing the mass spectrometric investigation.

The problem of locating double bonds in fatty acids is a classic one in mass spectrometry, and the subject was reviewed recently [6]. Of the many approaches, the strategy of derivatizing the carboxyl function to introduce a low ionization energy (IE) moiety is perhaps the most relevant to the work reported here. Derivatives that appear to give useful electron ionization (EI) mass spectra are pyrrolidides [19], picolinyl esters [20], 2-alkenylbenzoxazoles [21], and 2-alkenyl4,4-dimethyloxazolines [22]. The introduction of these moieties may serve to localize the charge (as a radical cation) and also allow for CRF, although this remains to be proved. Moreover, both the pyrrolidides [23] and the picolinyl esters [24] were evaluated previously as appropriate derivatives for the set of fatty acids investigated here.

Andersson et al. [23] demonstrated that the double bond positions of this series can be determined by using low-resolution EI on the pyrrolidides of the isomeric octadecadienoic acids. Their results indicate that all of the spectra show simple cleavage patterns, but not all of the pyrrolidide spectra were interpretable according to the rule developed for monoenic acids [25]. This rule states that "if an interval of 12 atomic mass units, instead of the regular 14, is observed between the most intense peaks of clusters of fragments containing $n$ and $n-1$ carbon atoms of the acid moiety, a double bond occurs between carbon $n$ and $n+1$ in the molecule." They did find, however, that each of the isomers has a different spectrum, and with enough reference compounds the identification of the positional isomers is possible.

The picolinyl ester derivatives of these acids were studied by Christie et al. [24], who used EI at $70 \mathrm{eV}$. Those authors indicated an almost universal utility of picolinyl esters for location of double bonds in isomers. The spectra were all examined for the series of ions that are $14 \mathrm{u}$ apart and result from the cleavages between successive methylene groups from the methyl end of the acid. A gap of $26 \mathrm{u}$ followed by one of $14 \mathrm{u}$ and then one of $26 \mathrm{u}$ represent the terminal and then the proximal double bonds. Difficulties of interpretation arise, however, when the double bonds are close to the carboxyl group.

\section{Experimental}

\section{Reagents and Procedures}

The earlier synthesis of the free acids was described by Christie and Holman [18], and samples of the acids were obtained from the Hormel Institute, Austin, Minnesota. Other reagents used were 3-nitrobenzyl alcohol (3-NBA), Lil, $\mathrm{Ba}(\mathrm{OH})_{2}$, triethanolamine, and glycerol, and all were obtained from Aldrich (Milwaukee, WI). To desorb the ions by FAB, a small amount (ca. $1 \mu \mathrm{g}$ ) of free acid was mixed with matrix on a copper probe tip. The lithiated species were desorbed from a matrix of 3-NBA and $15 \%$ glycerol saturated with LiI, the bariated ions from a matrix of $\mathrm{Ba}(\mathrm{OH})_{2}$ in 3-NBA and $15 \%$ glycerol, and the carboxylate anions from triethanolamine.

\section{Mass Spectrometry}

A Kratos MS-50 triple analyzer tandem mass spectrometer, which consists of a Nier-Johnson geometry highresolution mass spectrometer (MS-I) followed by an electrostatic analyzer (MS-II), was used to acquire CAD spectra [26]. It is equipped with a commercial Kratos FAB source, an Ion Tech saddle-field FAB gun (Ion Tech, Middlesex, England), and a Kratos DS-55 data system. Software for acquiring and processing MS/MS scans was written in this laboratory.

Precursor ions were produced in the FAB source by bombarding the sample (in the previously mentioned matrix) with 6-7-keV argon atoms. The ions were then accelerated through a potential of $8 \mathrm{kV}$. The FAB-desorbed precursor ions were mass-selected by using MS-I (ESA-I and the magnetic sector) at a resolution of approximately 2000-3000 (full width at $10 \%$ height). The selected ions were collisionally activated by introducing sufficient helium into the collision cell to reduce the beam of ions by approximately $30 \%$. Collision-activated decomposition was carried out in a collision cell located in the field-free region between MS-I and MS-II. Scanning of MS-II followed by averaging of the results of ten to thirty $20-\mathrm{s}$ scans gave the 


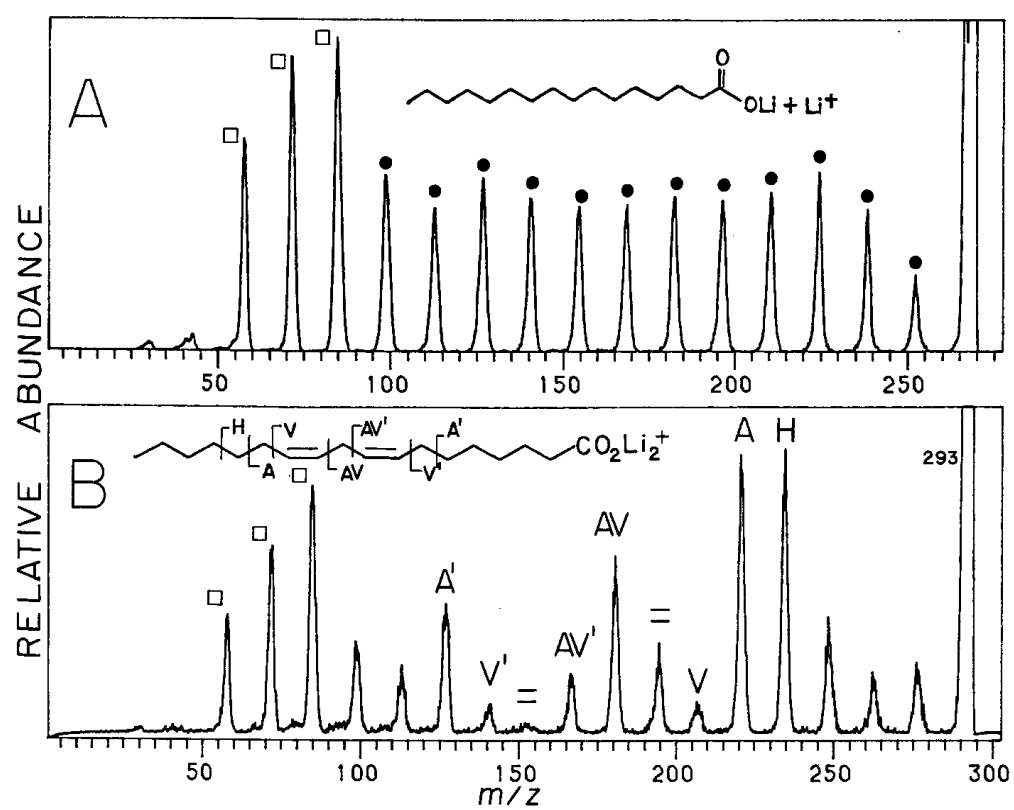

Figure 1. (a) CAD spectrum of the $[\mathrm{M}-\mathrm{H}+2 \mathrm{Li}]^{+}$of palmitic acid, showing a typical CRF pattern of a saturated acid. Charge-remote fragmentation denoted by $\boldsymbol{\bullet}$, charge-proximate fragmentation denoted by $\square, \mathrm{CO}_{2} \mathrm{Li}_{2}^{+}$at $m / z 58, \mathrm{CH}_{2} \mathrm{CO}_{2} \mathrm{Li}_{2}^{+}$at $m / z 72, \mathrm{C}_{2} \mathrm{H}_{2} \mathrm{CO}_{2} \mathrm{Li}_{2}^{+}$at $m / z$ 86. (b) $\mathrm{CAD}$ spectrum of $[\mathrm{M}-\mathrm{H}+2 \mathrm{Li}]^{+}$ion of 8,11-octadecadienoic acid (ODDA). Typical pattern created by two methylene-spearated double bonds. Double bond sites are marked with $=, \mathrm{V}$ represents ions formed by vinylic bond cleavage, $A$ represents ions formed by allylic bond cleavages, $H$ represents ions formed by homoallylic bond cleavage. Charge-proximate fragmentations are similar to those labeled in (a). The mass assignments for the first five peaks are 58,72, 85 and 86, 99 and 100, and 113. The peaks labeled $A^{\prime}, V^{\prime}, A V^{\prime}, A V, V, A$, and $H$ are assigned masses of 127, 141, 167, 181, 207, 221, and 235. The peak representing the cleavage of the distal double bond is at $m / z 195$. The mass assignments of the next three high-mass peaks are 249,263 , and 277, and the molecular ion has a mass of 293. Mass assignments were confirmed by unit resolution $B / E$ data.

CAD mass spectra of the product ions. The resultant spectra are sometimes termed mass-analyzed ion kinetic energy scan (MIKES) spectra.

\section{Results and Discussion}

Prior to the MS/CA/MS studies, a full-scan FAB spectrum was taken of each of the diene acids desorbed from a 3-NBA/Gly/LiI matrix. For each spectrum, the expected $[\mathrm{M}-\mathrm{H}+2 \mathrm{Li}]^{+}$ion was observed at $m / z$ 293, as was the $[\mathrm{M}+\mathrm{Li}]^{+}$at $m / z$ 287. Although these spectra indicate the presence of each acid by the appearance of the expected molecular ions, they contain no structural information. There is no detectable pattern of consistent neutral fragment losses seen at regular mass intervals; it is this pattern that indicates CRF.

\section{Reactions Occurring at the Functional Group}

Collision-activated decomposition spectra of the ions were obtained for each of three different forms of precursor: $[\mathrm{M}-\mathrm{H}]^{-},[\mathrm{M}-\mathrm{H}+2 \mathrm{Li}]^{+}$, and $[\mathrm{M}-\mathrm{H}+\mathrm{Ba}]^{+}$. These spectra are rich in structurally informative CRF patterns that are typically observed upon CA of closedshell ions of fatty acids and related materials. Details of this follow.

The normal CRF pattern observed upon CA of straight-chain acids (Figure 1a) is interrupted by the presence of the homoconjugated double bonds. This interruption creates a pattern that is characteristic of the homoconjugated double bond functionality and leads to identification of the functionality as well as its location.

Slight variations of the pattern accompany changes in functional group position and type of ionic precursor. As can be seen in Tables 1-3, the relative abundances of the ions created by cleavages at and around the double bond sites are not always the same. Nevertheless, the patterns remain easily recognizable in the spectra; one exception is the carboxylate anion of the 3,6 acid. The variations of the pattern and the characteristics of specific ionic precursors will be discussed in later sections.

The CAD spectrum of the dilithiated species of the 8,11 acid was selected for detailed discussion. The typical pattern characteristic of the homoconjugated double bonds, shown in Figure $1 \mathrm{~b}$, is composed of a series of nine peaks. It depicts an almost total interruption of $\mathrm{CRF}$ at the site of the proximal double bond. To the low-mass side of this is a very small peak, $\mathrm{V}^{\prime}$, which represents the ion formed by the vinylic cleavage, and then a large peak, $\mathrm{A}^{\prime}$, which corresponds to the ion formed by the facile allylic cleavage. 
The peak representing the ion formed by the cleavage at the distal double bond site is surprisingly intense, more intense than the adjoining one to its high-mass side, $V$, which represents an ion formed by cleavage of the vinylic bond. Continuing up the pattern (to higher mass), we next see two very intense peaks, $A$ and $H$, which tend to dominate the CRF patterns of this class of compounds. Although the peaks vary in intensity with respect to one another, they are generally easy to pick out. They represent ions formed by facile allylic $(\mathrm{A})$ and homoallylic $(\mathrm{H})$ cleavages

The last two peaks in the pattern are representative of ions formed by cleavages of the vinylic bonds located between the double bonds. Each bond is allylic (A) to one double bond and vinylic (V) to the other; hence we label the ions $A V$ and $A V^{\prime}$. The higher mass ion, $\mathrm{AV}$, formed by the cleavage of the bond allylic to the proximal double bond, is much more abundant than $A V^{\prime}$ when the double bonds are near the carboxyl end of the chain (with the exception of the 3,6 acid, for which there is major competition from a homolytic cleavage). As the functional group is moved down the chain, the abundances of these ions vary with respect to one another, becoming more nearly equal as the functional group is moved to the end of the chain. This trend is seen for the activation of all three precursors (i.e., $[\mathrm{M}-\mathrm{H}+2 \mathrm{Li}]^{+},[\mathrm{M}-\mathrm{H}+\mathrm{Ba}]^{+}$, and $[\mathrm{M}-\mathrm{H}]^{-}$).

There are mechanistic questions about the CAD of these acids. The mechanism of the cleavage of the two bonds located between the double bonds to give $\mathrm{AV}$ and $\mathrm{AV}^{\prime}$ is one question. It is also not clear why these two product ions differ in relative abundance and what effect the location of the functional group has on that relative abundance. The high abundance of the ion resulting from the cleavage at the distal double bond site is also unexpected. It is possible that a double bond isomerization takes place, but that brings up another question: Why is the distal but not the proximal double bond affected? Mechanistic possibilities to account for the nine peaks around the functional group are identified as follows, beginning with the proximal allylic cleavage, $\mathrm{A}^{\prime}$, and continuing up the pattern to the homoallylic cleavage, $\mathrm{H}$.

The cleavage of the proximal allylic bond, denoted by peak $\mathrm{A}^{\prime}$, probably does not occur by the $1,4 \mathrm{H}_{2}$ elimination mechanism. This would require the loss of a vinylic hydrogen, which seems unlikely given the abundance of this ion. A possible mechanism for this cleavage is a retroene (see Scheme II), which results in a terminally unsaturated fatty acid species [27].

$\mathrm{V}^{\prime}$, representing the proximal vinylic cleavage, is at low intensity. This can be accounted for by the $1,4 \mathrm{H}_{2}$

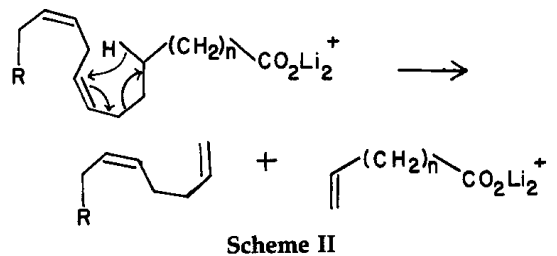

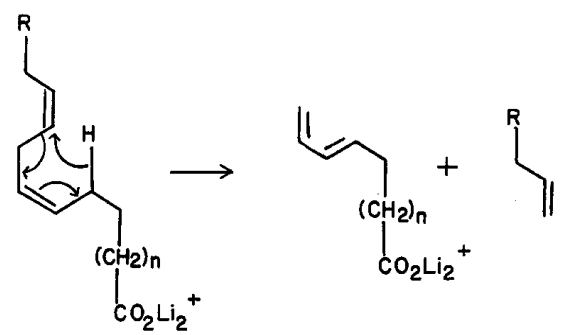

Scheme III

elimination mechanism, which would require the loss of a vinylic hydrogen. We have no suggestions for an alternative mechanism at this time.

$\mathrm{D}^{\prime}$, representing the ion formed upon cleavage of the proximal double bond, is also of low intensity. Some isomerization is necessary before the bond is cleaved. Unit mass resolution data (linked scans) indicate that the product ion has the mass of a fatty acid containing either a diene or a triple bond.

If the fragmentation representing $\mathrm{AV}^{\prime}$ is a $1,4 \mathrm{elim}$ ination of hydrogen, then both hydrogens involved must be vinylic. This cleavage is the one that shows the most change in abundance of the product ion with change in double bond location. Further investigation is needed to be certain of the mechanism.

The relative intensity of the $\mathrm{AV}$ peak leads us to believe that the corresponding fragmentation mechanism is not the $1,4 \mathrm{H}_{2}$ elimination, which would again involve two vinylic hydrogens. The product would be a terminal allene. A more likely mechanism is shown in Scheme III. This involves an allylic hydrogen transfer and formation of a conjugated diene at the terminus.

The cleavage of the distal double bond gives peak D. The principal loss is of $\mathrm{C}_{n} \mathrm{H}_{2 n}$ to give possibly a fatty acid species with conjugated double bonds at the terminus. The mechanism must be more complex than a simple 1,4 elimination of hydrogen.

$\mathrm{V}$, the peak representing proximal vinylic cleavage, would again involve transfer of vinylic hydrogen if the mechanism were the $1,4 \mathrm{H}_{2}$ elimination and would lead to the formation of a fatty acid species with a terminal triple bond. The low abundance of this ion is consistent with the hypothesis but does not prove the mechanism.

A, arising from cleavage of the proximal allylic bond, is unlikely to be caused by $1,4 \mathrm{H}_{2}$ elimination because of the abundance of the resulting ion. Again a loss of a vinylic hydrogen is required. Another possibility is a 1,4 conjugate elimination, which would lead to a terminally conjugated fatty acid species [27].

The homoallylic cleavage peak, $\mathrm{H}$, seems likely to occur by $1,4 \mathrm{H}_{2}$ elimination. The high abundance indicates a very stable product ion, whose presence would be in accord with a facile $1,4 \mathrm{H}_{2}$ elimination mechanism (see Scheme IV). Moreover, one of the hydrogen atoms involved in the 1,4 loss is allylic. The process results in a terminally unsaturated ion, and in this case that terminal unsaturation is conjugated with the second double bond, thereby stabilizing the product ion. This 


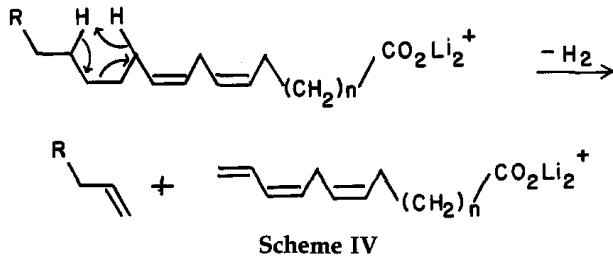

homoallylic cleavage is also facile for fatty acids containing a single double bond [9-11], but no explanation of stabilization was given in those reports.

\section{Lithium Cationized}

The $[\mathrm{M}-\mathrm{H}+2 \mathrm{Li}]^{+}$ions undergo extensive $\mathrm{CRF}$, making a structural determination quite simple. The pattern for the homoconjugated double bonds is easily picked out of the spectra, independent of the location of this functional group with respect to the lithiated carboxyl group (Figure 2). The relative abundances of
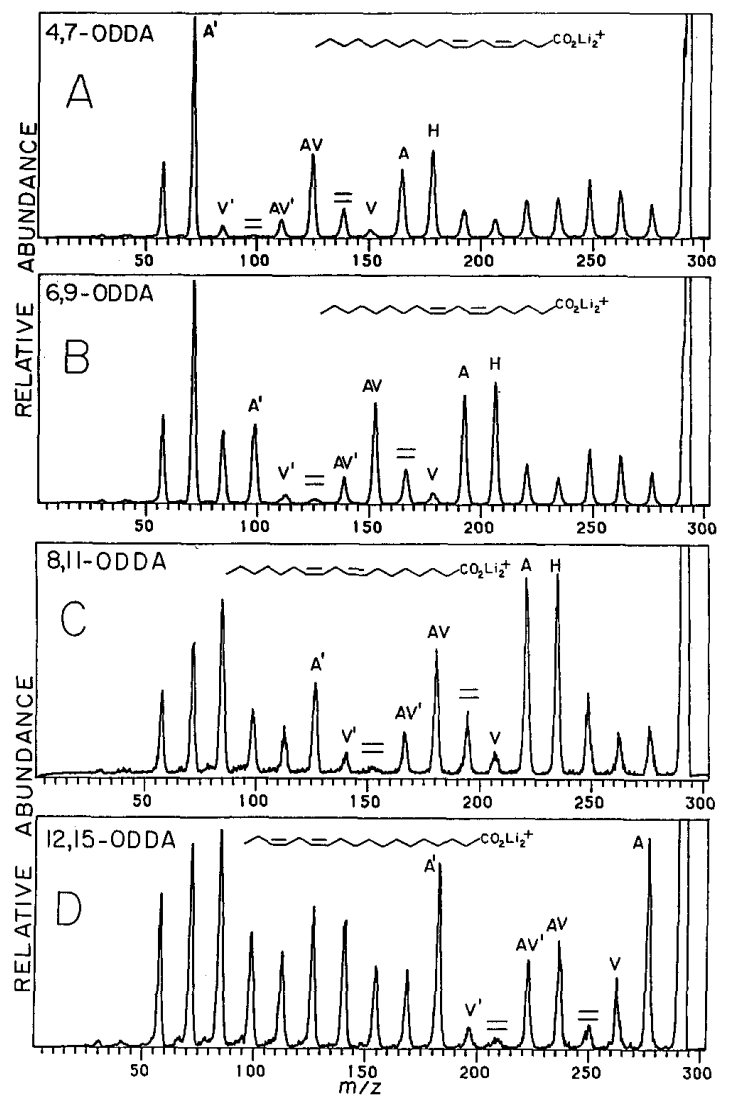

Figure 2. CAD spectra of [M-H $+2 \mathrm{Li}]^{+}$ions of (a) 4,7-ODDA, (b) 6,9-ODDA, (c) 8,11-ODDA, and (d) 12,15-ODDA. Peaks are labeled as in Figure $1 \mathrm{~b}$. The mass of the molecular ion in each of these spectra is 293 . The mass assignments for the peaks labeled $\mathrm{A}^{\prime}, \mathrm{V}^{\prime}, \mathrm{AV}^{\prime}, \mathrm{AV},=, \mathrm{V}, \mathrm{A}$, and $\mathrm{H}$ are (a) 71 and $72,85,111$, 125, 139, 151, 165, and 179; (b) 99 and 100, 113, 139, 153, 167, 179, 193, and 207; (c) 127, 141, 167, 181, 195, 207, 221, and 235; (d) 183, 197, 223, 237, 251,263, and 277. The assignments were confirmed by a linked $\mathrm{B} / \mathrm{E}$ scan for the spectrum in (b). the nine ions involved in the pattern have very distinctive trends (Table 1). The most abundant ion is always a result of an allylic or homoallylic cleavage; the least abundant ion is always a result of reaction at the proximal double bond site. The products of vinylic cleavages are very similar in relative abundance, and the cleavage of the proximal vinyl $\mathrm{C}-\mathrm{C}$ bond is less facile.

In addition to the ions produced by CRF, several low-mass ions are produced that appear to be products of homolytic cleavages. Unit resolution product ion spectra were obtained by using $\mathrm{B} / \mathrm{E}$ linked scans. Characteristic peaks seen at the low-mass end of the spectrum represent the radical cations $\mathrm{CO}_{2} \mathrm{Li}_{2}{ }^{+}, \mathrm{CH}_{2} \mathrm{CO}_{2} \mathrm{Li}_{2}{ }^{+*}, \mathrm{CH}_{2} \mathrm{CH}_{2} \mathrm{CO}_{2} \mathrm{Li}_{2}{ }^{+*}$, and $\left(\mathrm{CH}_{2}\right)_{3} \mathrm{CO}_{2} \mathrm{Li}_{2}{ }^{+}$at $m / z 58,72,86$, and 100 , respectively. These ions are odd-electron and possible distonic species and may be produced by a chargeproximate process.

The unit resolution $\mathrm{d}$ ita also show that there are substantial peaks at $\mathrm{m} / \mathrm{z} 85$ and 99. These represent even-electron ions, $\mathrm{CH}_{2}=\mathrm{CHCO}_{2} \mathrm{Li}_{2}{ }^{+}$and $\mathrm{CH}_{2}=\mathrm{CHCH}_{2} \mathrm{CO}_{2} \mathrm{Li}_{2}{ }^{+}$, which are the lowest mass products possible for CRF via the proposed $1,4 \mathrm{H}_{2}$ elimination. Competing processes result in unresolved multiplets in the low-resolution CA (or MIKES) spectra and are characterized by a different energy shift than the singlet peaks. Neglect of this energy shift difference may result in incorrect mass assignments.

\section{Barium Cationized}

When the desorbed $[\mathrm{M}-\mathrm{H}+\mathrm{Ba}]^{+}$ions are collisionally activated, the spectra are dominated by oddelectron species resulting from charge-proximate fragmentation. The closed-shell ions that result from CRF are also observed, and the distinctive pattern that is characteristic of the functional group can be seen. The CRFs are much more facile than those occurring for the lithiated species. Nevertheless, they appear suppressed because of the dominant charge-proximate reactions (Figure 3).

Relative abundances of the ions formed by reactions in the vicinity of the double bonds are given in Table 2 . Although the relative abundances depend somewhat on the location of the functional group, specific trends similar to those of the lithiated species can be seen as the functional group is moved down the chain.

When the unsaturation is close to the carboxyl group (e.g., in the 3,6 position), some loss of $\mathrm{CO}_{2}$ occurs from the bariated ions. This is indicated by the enhancement of the peak at $m / z 373$, not observed in the normal CRF pattern. Evidence for loss of $\mathrm{CO}_{2}$ also appears in the $[\mathrm{M}-\mathrm{H}]^{-}$anion CA spectrum but not in that of the lithiated species. This suggests that the bariated species may undergo a reaction such as depicted in Scheme V.

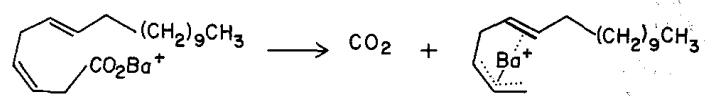

Scheme V 
Table 1. Relative abundances ${ }^{a}$ of ions representing cleavages around the double bonds in a series of octadecadienoic acids (ODDA):

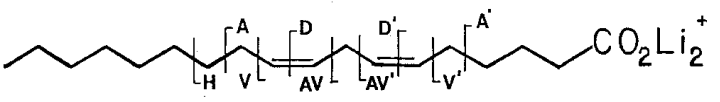

\begin{tabular}{|c|c|c|c|c|c|c|c|c|c|}
\hline $\begin{array}{l}\text { Bond } \\
\text { positions }\end{array}$ & $A^{\prime}$ & $V^{\prime}$ & $D^{\prime}$ & $A V^{\prime}$ & AV & $\mathrm{D}$ & V & A & $\mathrm{H}$ \\
\hline 3,6-ODDA & $63^{b}$ & $20^{b}$ & $5^{b}$ & $100^{b}$ & 46 & 12 & 10 & 52 & 52 \\
\hline 4,7-ODDA & $100^{b}$ & $7^{b}$ & 1 & 11 & 43 & 18 & 7 & 38 & 53 \\
\hline 5,8-ODDA & $85^{b}$ & 9 & 2 & 16 & 78 & 33 & 9 & 86 & 100 \\
\hline 6,9-ODDA & 56 & 7 & 5 & 24 & 77 & 31 & 10 & 92 & 100 \\
\hline $7,10-O D D A$ & 49 & 13 & 7 & 22 & 79 & 34 & 15 & 100 & 88 \\
\hline 8,11-ODDA & 43 & 13 & 5 & 22 & 65 & 31 & 12 & 99 & 97 \\
\hline 9,12-ODDA & 69 & 14 & 6 & 31 & 55 & 30 & 17 & 100 & 89 \\
\hline $10,13-$ ODDA & 48 & 9 & 8 & 23 & 44 & 25 & 14 & 100 & 58 \\
\hline $11,14-O D D A$ & 45 & 8 & 4 & 23 & 37 & 6 & 15 & 100 & 31 \\
\hline $12,15-O D D A$ & 88 & 12 & 5 & 44 & 56 & 13 & 39 & 100 & NA \\
\hline $13,16-O D D A$ & 100 & 17 & 12 & 49 & 46 & 16 & 45 & NA & NA \\
\hline
\end{tabular}

a Expressed as percentage of the most abundant peak height in the region.

b Interference from charge-proximate reaction.

There are certain advantages to using the bariated species instead of the lithiated or the carboxylate anion [28]. The higher mass resulting from the addition of the barium places the molecular ion in a region of the spectrum where there is less chemical noise. The mass defect of this species also allows for separation from the existing chemical noise with the use of moderate resolving power. One further advantage is that most of the ion current is localized as the $[\mathrm{M}-\mathrm{H}+\mathrm{Ba}]^{+}$ ion, unlike the lithiated species, where the $[\mathrm{M}+\mathrm{H}]^{+}$ and $\left[\mathrm{M}+\mathrm{Li}^{+}\right.$ions are also desorbed.

\section{Carboxylate Anion}

The chemistry that some of the carboxylate anions exhibit is very different from that of the lithiated species, although a portion of it is seen in the reactions of the bariated ions. These differences are attributed to a less strongly localized charge for carboxylates than for metal ion cationized species. Moreover, there are charge-directed processes that can occur for the carboxylates (as well as for protonated species) to give losses of stable molecules (e.g., $\mathrm{CO}_{2}, \mathrm{H}_{2} \mathrm{O}$ ). These losses are difficult to envision for metal ion cationized species. As a result of charge movement away from the carboxylate, significant losses of $\mathrm{H}_{2} \mathrm{O}$ and $\mathrm{CO}_{2}$ occur from the vicinity of the charge site for certain of the acids. These losses are observed as high-mass peaks in the spectra, and the normal CRF pattern is attenuated with respect to peaks representing these losses (Figure 4).

Table 2. Relative abundances ${ }^{a}$ of ions representing cleavages around the double bonds in a series of octadecadienoic acids (ODDA):

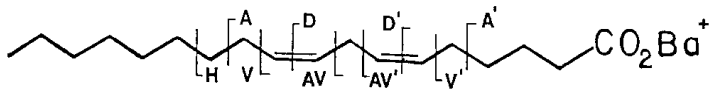

\begin{tabular}{|c|c|c|c|c|c|c|c|c|c|}
\hline $\begin{array}{l}\text { Bond } \\
\text { positions }\end{array}$ & $A^{\prime}$ & $V^{\prime}$ & $D^{\prime}$ & $A V^{\prime}$ & AV & D & V & A & $\mathrm{H}$ \\
\hline 3,6-ODDA & $26^{b}$ & $14^{b}$ & $5^{b}$ & $100^{b}$ & 26 & 4 & 60 & 13 & 14 \\
\hline 4,7-ODDA & $100^{b}$ & $11^{\mathrm{b}}$ & 1 & 7 & 10 & 6 & 1 & 10 & 25 \\
\hline $5,8-O D D A$ & $100^{b}$ & 5 & 3 & 7 & 20 & 9 & 5 & 25 & 33 \\
\hline $6,9-\mathrm{ODDA}$ & 86 & 17 & 9 & 17 & 77 & 30 & 11 & 90 & 100 \\
\hline $7,10-O D D A$ & 67 & 18 & 10 & 24 & 76 & 28 & 15 & 91 & 100 \\
\hline 8,11-ODDA & 77 & 19 & 5 & 17 & 83 & 26 & 12 & 100 & 95 \\
\hline $9,12-\mathrm{ODDA}$ & 98 & 18 & 5 & 28 & 75 & 26 & 13 & 100 & 78 \\
\hline $10,13-\mathrm{ODDA}$ & 82 & 14 & 5 & 27 & 78 & 24 & 18 & 100 & 66 \\
\hline $11,14-\mathrm{ODDA}$ & 84 & 17 & 6 & 24 & 73 & 11 & 14 & 100 & 39 \\
\hline $12,15-\mathrm{ODDA}$ & 100 & 15 & 4 & 32 & 58 & 10 & 16 & 67 & NA \\
\hline 13,16-ODDA & 100 & 12 & 5 & 32 & 35 & 7 & 11 & NA & NA \\
\hline
\end{tabular}

a Expressed as percentage of the most abundant peak height in the region.

b Interference from charge-proximate reaction. 

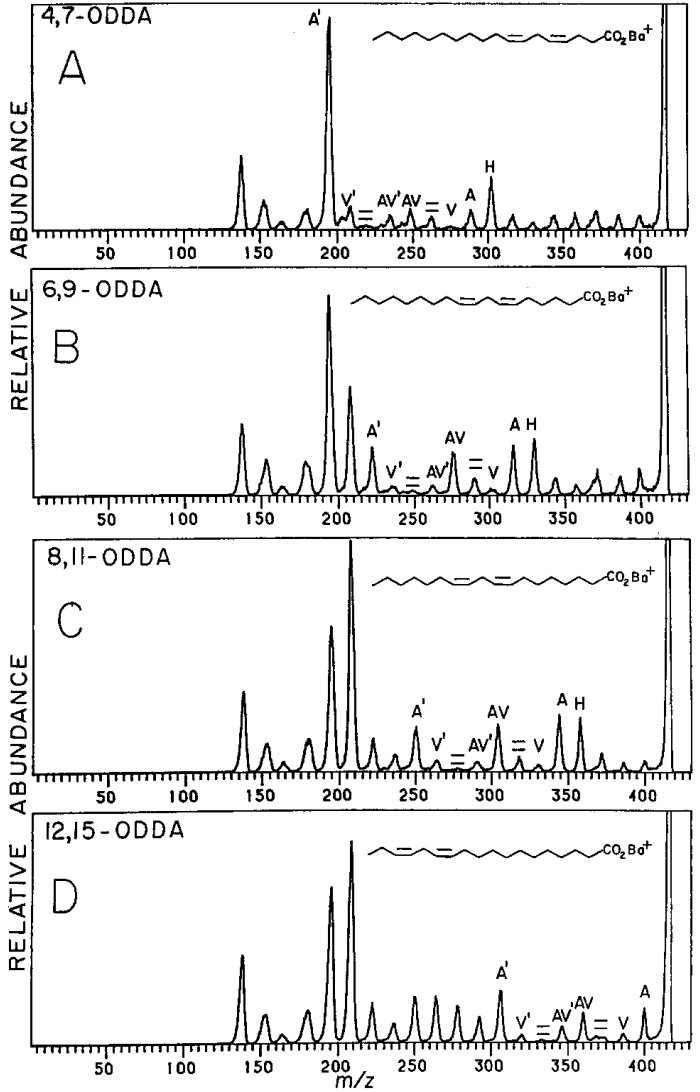

Figure 3. CAD spectra of $[\mathrm{M}-\mathrm{H}+\mathrm{Ba}]^{+}$ions of (a) 4,7-ODDA, (b) 6,9-ODDA, (c) 8,11-ODDA, (d) 12,15-ODDA. Peaks are labeled as in Figure $1 \mathrm{~b}$. The peak of the molecular ion in each of the spectra is at $m / z$ 417. The mass assignments for the peaks labeled $\mathrm{A}^{\prime}$, $\mathrm{V}^{\prime}, \mathrm{AV}^{\prime}, \mathrm{AV},=, \mathrm{V}, \mathrm{A}$, and $\mathrm{H}$ are (a) 195 and 196, 209, 235, 249, 263, 275, 289, and 303; (b) 223, 237, 263,277, 291, 303, 317, and 331; (c) 251, 265, 291, 305, 319, 331, 345, and 359; (d) 307, 321, $347,361,375,387$, and 401 . The assignments were confirmed by a linked $B / E$ scan for the spectrum in (b).

When the double bonds are located near the carboxyl group, loss of $\mathrm{CO}_{2}$ dominates the spectra. In the case of the 3,6 acid, the CRF appears completely preempted by the loss of neutral $\mathrm{CO}_{2}$. As the functional group is moved further down the chain, we see instead a large amount of water loss (see Scheme VI) [29]. It is not until the double bonds are moved down to the 7,10 position that CRF is the predominant decomposition pathway. Fatty acids that have the double bonds located in this or more remote positions fragment in a fashion similar to that for the lithium- and barium-cationized species. The functional groups can then be easily located on the basis of a CRF pattern in the spectra that is very similar to that described for the lithiated ions.

Although CRF is not the predominant fragmentation pathway for all the carboxylate anions of the acids, the CRF pattern does show some variations from one isomer to another. As can be seen in Table 3, there
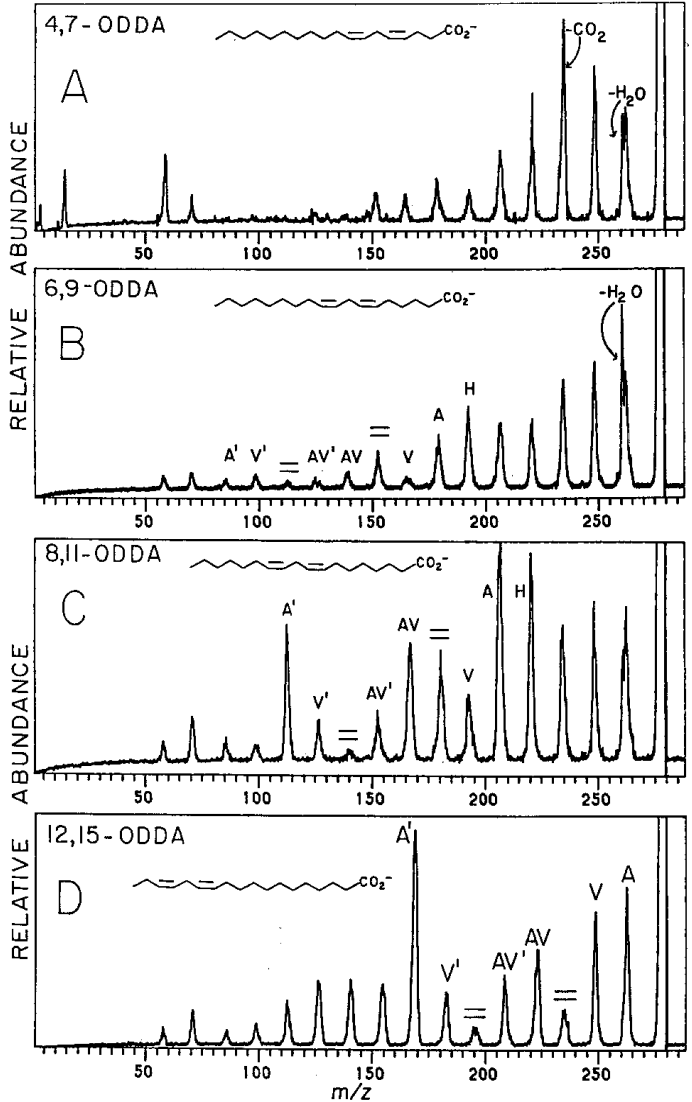

Figure 4. CAD spectra of $[\mathrm{M}-\mathrm{H}]^{-}$anions of (a) 4,7-ODDA, (b) 6,9-ODDA, (c) 8,11-ODDA, (d) 12,15-ODDA. Peaks are labeled as in Figure $1 \mathrm{~b}$. The peak of the molecular ion in each of the spectra is at $m / z$ 279. The mass assignments for the peaks labeled $\mathrm{A}^{\prime}$, $\mathrm{V}^{\prime}, \mathrm{AV}^{\prime}, \mathrm{AV},=, \mathrm{V}, \mathrm{A}$, and $\mathrm{H}$ are (b) $85,99,125,139,153,165$, 179 , and 193; (c) 113,127, 153,167, 181, 193, 207, and 221; (d) $169,183,209,223,237,249$, and 263.

are a few major differences in the trends observed in the relative abundances of the nine ions that comprise the pattern for the homoconjugated double bond functional group. The most significant difference is the surprisingly abundant ion resulting from the cleavage at the distal double bond. The unexpected abundance from the proximal vinylic cleavage is also an indication that there may be fragmentation pathways different from those of the cationized species.

\section{Conclusion}

The lithiated ions have CAD spectra that are dominated by CRF. This allows for structural interpretation of the spectra and identification and location of the

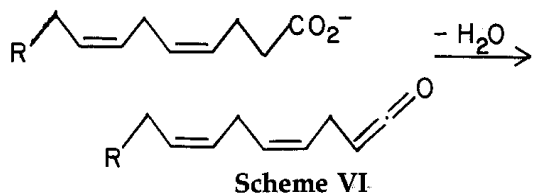


Table 3. Relative abundances ${ }^{a}$ of ions representing cleavages around the double bonds in a series of octadecadienoic acids (ODDA):

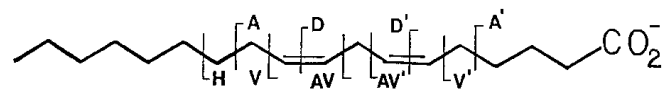

\begin{tabular}{|c|c|c|c|c|c|c|c|c|c|}
\hline $\begin{array}{l}\text { Bond } \\
\text { positions }\end{array}$ & $A^{\prime}$ & $V^{\prime}$ & $D^{\prime}$ & $\mathrm{AV}^{\prime}$ & AV & D & v & A & $\mathrm{H}$ \\
\hline 3,6-ODDA & $N^{b}$ & $N A^{b}$ & $N A^{b}$ & $N A^{b}$ & $N^{b}$ & $N^{b}$ & $N^{b}$ & $\mathrm{NA}^{\mathrm{b}}$ & $N A^{b}$ \\
\hline 4,7-ODDA & 100 & 41 & 4 & 9 & 7 & 15 & 12 & 45 & 43 \\
\hline 5,8-ODDA & 50 & 21 & 15 & 22 & 16 & 41 & 20 & 70 & 100 \\
\hline $6,9-\mathrm{ODDA}$ & 14 & 20 & 11 & 14 & 23 & 48 & 16 & 67 & 100 \\
\hline 7,10-ODDA & 27 & 24 & 11 & 17 & 35 & 39 & 23 & 61 & 100 \\
\hline $8,11-O D D A$ & 61 & 18 & 5 & 23 & 54 & 51 & 30 & 100 & 94 \\
\hline $9,12-O D D A$ & 53 & 16 & 3 & 17 & 37 & 29 & 41 & 100 & 87 \\
\hline $10,13-\mathrm{ODDA}$ & 74 & 18 & 5 & 30 & 42 & 44 & 49 & 100 & 71 \\
\hline $11,14-\mathrm{ODDA}$ & 78 & 14 & 7 & 30 & 43 & 14 & 41 & 100 & 43 \\
\hline $12,15-\mathrm{ODDA}$ & 100 & 25 & 8 & 33 & 44 & 17 & 62 & 73 & NA \\
\hline $13,16-\mathrm{ODDA}$ & 100 & 20 & 8 & 41 & 44 & 17 & 34 & NA & NA \\
\hline
\end{tabular}

a Expressed as percentage of the most abundant peak height in the region.

${ }^{b}$ Interference from charge-proximate reaction.

functional group from a readily identifiable interruption of the normal CRF pattern. Other neutral losses do not compete with the CRF.

The CRF occurs in a consistent and predictable manner for the lithiated acids with the functional group at any position, and structural identification is straightforward except for the 3,6 acid, where a chargeproximate reaction competes with CRF. There are differences, however, in the relative abundances of the ions resulting from the cleavage of the bonds between the double bonds and of the ion formed by the cleavage at the distal double bond site. These issues will be addressed in future work.

Although the bariated ions show structurally informative CRF in their CA spectra, they undergo a significant amount of charge-proximate chemistry to give intense peaks in the lower mass region of their spectra. The pattern associated with the functional group does not change significantly as the functional group is moved down the chain, with the exception that there is a loss of $\mathrm{CO}_{2}$ for the 3,6-octadecadienoic acid.

The CA of the $[\mathrm{M}-\mathrm{H}]^{-}$anion can also be used for structural determination of modified fatty acids. It is not the method of choice, however, if cationization can be chosen. The CA spectra are complicated by reactions other than charge-remote reactions, which compete and sometimes preempt the structurally informative CRF Neutral losses of $\mathrm{H}_{2} \mathrm{O}$ and $\mathrm{CO}_{2}$ dominate the spectra when the double bonds are in the vicinity of the carboxylate.

Although prior determination of these isomeric acids by EIMS was successful in determining the double bond location $[23,25]$, analysis by FAB and MS/CA/MS appears to be superior to the EI methods in many ways. Derivatization is not required, and the interpretation of the spectra is much more straightforward. The CA spectra show easily recognizable pat- terns that give the position of the double bonds at a glance. Derivatization followed by GC/MS does offer the capacity to determine mixtures of isomers and fatty acids with similar nominal mass; however, separation of homologues and fatty acids of varying mass can be achieved by using FAB and MS/MS, provided the components do not exist as complicated mixtures of isomers.

\section{References}

1. Adams, J.; Gross, M. L. Org. Mass Spectrom. 1988, 23, 307-316.

2. Tomer, K. B.; Jensen, N. J.; Gross, M. L. Anal. Chem. 1986, $58,2429-2433$.

3. Jensen, N. J.; Tomer, K. B.; Gross, M. L. J. Am. Chem. Soc. 1985, 107, 1863-1868.

4. Adams, J.; Gross, M. L. J. Am. Chem. Soc. 1989, 111, 435-440.

5. Gross, M. L.; Jensen, N. J.; Lippstreu-Fisher, D. L.; Tomer, K. B. In Mass Spectrometry in the Health and Life Sciences; Burlingame, A. L.; Castagnoli, N., Jr., Eds; Elsevier: Amsterdam, 1985; pp 209-238.

6. Jensen, N. J.; Gross, M. L. Mass Spectrom. Rev. 1987, 6, 497-536.

7. Adams, J.; Deterding, L. J.; Gross, M. L. Spectrosc. Int. J. 1987, 5, 199-228.

8. Jensen, N. J.; Tomer, K. B.; Gross, M. L.; Lyon, P. A. In Desorption Mass Spectrometry-Are SIMS and FAB the Same?; Lyon, P. A., Ed.; American Chemical Society, Washington; DC, 1985; pp 194-208.

9. Tomer, K. B.; Crow, F. W.; Gross, M. L. J. Am. Chem. Soc. 1983, 105, 5487-5488.

10. Jensen, N. J.; Tomer, K. B.; Gross, M. L. Anal. Chem. 1985, 57, 2018-2021.

11. Adams, J.; Gross, M. L. Anal. Chem. 1987, 59, 1576-1582.

12. Jensen, N. J.; Gross, M. L. Lipids 1986, 21, 362-365.

13. Burr, G. O.; Burr, M. M. J. Biol. Chem. 1929, 82, 345-367.

14. Stoffel, W.; Ahrens, E. H. J. Lipids Res. 1959, 1, 139-149.

15. Dalgarno, L.; Birt, L. M. Biochem J. 1963, 87, 586-596.

16. Kishimoto, Y.; Radin, N. S. J. Lipid Res. 1964, 5, 98-102. 
17. Fulco, A. J.; Mead, J. F. J. Biol. Chem. 1960, 235, 3379-3384.

18. Christie, W. W.; Holman, R. T. Chem. Phys. Lipids 1967, 1, 407-423.

19. Vetter, W.; Walther, W.; Vecchi, M. Helv. Chim. Acta 1971, 54, 1599-1605.

20. Harvey, D. J. Biomed. Mass Spectrom. 1982, 9, 33-38.

21. Yu, Q.; Zhang, J.; Haung, Z. Biomed. Mass Spectrom. 1986, 13, 212-216.

22. Zhang, J.; Yu, Q.; Liu, B.; Huang, Z. Biomed. Mass Spectrom. $1988,15,33-34$.

23. Andersson, B. A.; Christie, W. W.; Holman, R. T. Lipids 1975, 10, 215-219.
24. Christie, W. W.; Brechany, E. Y.; Holman, R. T. Lipids 1987, 22, 224-228.

25. Andersson, B. A.; Holman, R. T. Lipids 1974, 9, 185-190.

26. Gross, M. L.; Chess, E. K.; Lyon, P. A.; Crow, F. W.; Evan, S.; Tudge, H. Int. I. Mass Spectrom. Ion Phys. 1982, 42, 243-254.

27. Contado, M. J.; Adams, J.; Jensen, N. J.; Gross, M. L. Proceedings of the 37th ASMS Conference on Mass Spectrometry and Allied Topics, 1989, p 654.

28. Davoli, E.; Gross, M. L. J. Am. Soc. Mass Spectrom., submitted.

29. Jensen, N. J.; Gross, M. L. Org. Mass Spectrom., submitted. 